\title{
Panoptic performativity and school inspection regimes: disciplinary mechanisms and life under special measures
}

\section{Introduction}

In this paper I examine how education policy in England and Wales has led to increased accountability, and use research data to examine one aspect of this accountability - school inspection in England. I concentrate on OfSTED, the school inspection service, and Special Measures, the system of intensive inspection regimes applied to schools deemed to be 'failing'.

OfSTED, and particularly Special Measures, form an important part of the disciplinary regime in education. 'The exercise of school inspection (is) one of improvement through threat and fear, an intentionally disciplining role' (Lonsdale and Parsons 1998, p 110). There are clear links between Special Measures regimes and Foucault's (1977) work on discipline. Foucault (1977, p 170) wrote that

the success of disciplinary power derives no doubt from the use of simple instruments; hierarchical observation, normalizing judgement and their combination in a procedure that is specific to it, the examination

The examination, in the guise of inspections, is part of the increasing culture of accountability in education, which has created a system in which disciplinary mechanisms are used widely, although surveillance of teachers has always been on the political agenda. For example, in 1834, Mr W.F Lloyd, Secretary to the Sunday School Union wrote in his Report on the State of Education, 'There should be, with respect to education, a vigilant eye everywhere, and many schools have, for want of that, sunk very materially indeed' (MacClure 1979, p 33).

In this paper I will argue that this vigilant eye is increasingly everywhere, through the increasing use of accountability in education, and no more so than within a Special Measures 
regime. I use the idea of 'panoptic performativity' to explore the experience of undergoing inspection. Panoptic performativity describes a regime in which frequency of inspection and the sense of being perpetually under surveillance leads to teachers performing in ways dictated by the discourse of inspection in order to escape the regime. Lessons are taught to a rigidly prescribed routine, school documentation and policies closely mirror the accepted discourses of school effectiveness and the whole school effort is directed away from education and towards passing inspection.

\section{Special Measures - the Policy Context}

The policy background in which this study is placed is the increasing system of accountability in which teachers in England work. Gleeson and Gunter (2001) chart the change in autonomy of teachers. They characterise the period from the 1960 s to the mid-1980s as 'relative autonomy'. In this period teachers were accountable to themselves through informal reflection and peer review. They worked within curricula established by headteachers and there was some voluntary appraisal of their teaching performance. Any evidence about performance was collected informally and there was a professional emphasis on ethical commitment. They refer to the period from the 1980 s to the 1990 s as 'controlled autonomy'. During this period teachers were accountable to themselves through formal reviews. Line management systems were set up and the senior management team put these systems under surveillance with the introduction of mandatory appraisals from 1991. Evidence was formalised through classroom observation and teachers were set targets from professional development discussions based on data from self reviews and observations.

Between 1988 and 1994 there was at least one education act passed per year (Tomlinson 2001), which led to teachers becoming 'a technical workforce to be managed and controlled rather than a profession to be respected' (ibid p 36). Since the 1988 Education Reform Act, there has been a shift in accountability from teacher professionalism, with accountability to themselves, their colleagues and their students (self-regulation), to accountability to agencies 
such as the Qualifications and Curriculum Authority (QCA) ${ }^{1}$, OfSTED and the Teacher Training Agency $(\mathrm{TTA})^{2}$. The accepted discourse presented by government and the media is that teachers are in need of reform, and this reform needs to me monitored by increased surveillance. As Poulson (1998, p 420) argues, 'few people would disagree that increased accountability is a good thing; or that standards in schools should be raised... However accountability is an ambiguous term in discourses about education; within it are condensed a range of meanings and emotions'. Accountability, it seems, is unquestionably 'a good thing', and the mechanisms through which accountability is achieved are increasingly accepted as a part of the education system. Avis (2005: 211), writing about accountability in further education notes the existence of a 'regime of truth that refuses other conceptualisations of good practice, which therefore become silenced and are denied legitimacy'.

Since 2000, teachers have been controlled by what Gleeson and Gunter (2001) call 'productive autonomy'. Teachers are now accountable through formal audits of student learning outcomes controlled by senior management. Teaching is controlled by the national curriculum and a performance framework that is backed up by performance management pay and target-setting. Evidence about performance is based on pupil outcomes, classroom observation, and personal statements. Pupils become objects and targets and the headteacher and senior management team are publicly accountable. This is the development of an evaluative state with the establishment of a 'so-called independent watchdog in the form of OfSTED' (Elliott 2001, p 192).

Surveillance of schools is achieved by the system of school inspection as it has operated in England and Wales since the 1992 Education Act. Before this, from 1868 to 1992, the relatively independent Her Majesty's Inspectorate (HMI) carried out school inspections. Their periodic inspections were designed to provide an external view of schools to assist Local Education Authorities (LEAs) in effecting improvement. The Education Act of 1992 led to the creation of Office for Standards in Education (OfSTED), which is a privatised inspection

\footnotetext{
${ }^{1}$ The QCA, formally the Schools Curriculum and Assessment Authority (SCAA), set up in the 1993 Education Act as the government's curriculum and assessment advisory board.

${ }^{2}$ The TTA was set up by the 1994 Education Act to oversee the system of teacher training in England and Wales.
} 
system. Inspection teams, who have to bid for contracts, are led by a Registered Inspector, and inspect schools according to a criteria-based system. Following the inspection, the Registered Inspector reports to OfSTED and to the school in a publicly available document. The school then produces a summary report for parents and governors and an action plan to address any concerns raised in the report.

If a school is not seen to be providing an acceptable standard of education, it becomes subject to Special Measures and subsequently receives termly visits from Her Majesty's Inspectorate (HMI) to monitor progress. If the school is judged to have made sufficient improvements the school is removed from Special Measures following a full inspection. In extreme cases, if OfSTED does not observe improvement, the school is closed down. By September 1999, 900 schools had been put into Special Measures, approximately 3\% of secondary schools (OfSTED 1999).

It is not my intention to argue that schools judged as 'failing' should not be subject to some form of intervention, but to illustrate the deficiencies of a system which dictates that in order to be removed from Special Measures teachers must adhere strictly to a rigid and predetermined recipe for success. This 'recipe' is based on school effectiveness theories, and uses performativity and normalisation as its mechanisms. It is assumed that all schools can follow the same recipe for success, and any deviation from this norm can be an indicator that a school is failing, which of course ignores the individual socio-economic contexts in which schools are located. Performativity becomes the mechanism in which schools demonstrate, through documentation and pedagogy that they have been normalised. This links with the work of Wilcox and Gray (1996) who see inspection it is part of an audit culture which involves the use of quantitative data concerned with efficiency, quality and performance. A key section in OfSTED reports is on value-for-money and financial planning which is a way of making a qualitative survey appear to be grounded in facts and statistics..

\section{Performativity, normalisation and discourses of school effectiveness}


Performativity is about performing the normal within a particular discourse. In the context of school inspection this means that lessons are taught in a particular way and school policies and documentation reflect the expected discourse. Performativity is a term first used by Lyotard in 1984, when he suggested that post-modern society is obsessed with efficiency and effectiveness. This has led to all kinds of businesses, (and more recently schools themselves), being judged in terms of outcome and performance. Thus league tables, SATs results and inspection reports are increasingly the measurements by which schools and teachers are judged. Performativity is linked with the increased accountability and surveillance under which teachers find themselves and their schools being judged in terms of outcome and performance. Jeffrey $(2002, \mathrm{p} 1)$ notes that

A performativity discourse currently pervades teachers' work. It is a discourse that relies on teachers and schools instituting self-disciplinary measures to satisfy newly transparent public accountability and it operates alongside a market discourse

Within inspection regimes, schools are judged as successful when conforming to previously defined criteria. These are linked to school effectiveness research, the findings of which are essentially neutral descriptions of good practice in successful schools, but have been used as powerful mechanisms for dictating normality. Sammons, Hillman and Mortimore (1995, p 8), in their research on the eleven key characteristics of effective schools, identified the following factors; leadership, shared vision and goals, an orderly learning environment, emphasis on learning, purposeful teaching, high expectations, positive reinforcement, monitoring of pupil progress, a high level of pupil involvement in the life of the school, positive home-school partnerships and an ethos which enables the school to become a learning organisation.

The findings of school effectiveness research are unsurprising. However, it could be argued that the characteristics of effective schools are not the cause but the effect. Many of the effectiveness factors also form circles of self-fulfilling prophecy - schools with high standards of behaviour can be found to have good patterns of discipline, schools with good resources have good use of their facilities, schools with low staff turnover have continuity in teaching. 
Rea and Weiner (1998, p 27) note 'The list of factors promoting school effectiveness seems at first glance to state the obvious - that effective schools are...effective'. The list also ignores the socio-economic context of the school, its catchment area, indicators of poverty and deprivation and the history of the school. Johnson (1999) stresses the importance of the social background of the students, arguing that if, for example, the majority of students in a school come from families in which three generations have been unemployed, it is unrealistic to expect those children to value the life chances that education can bring.

In this context it is worrying that school effectiveness research has been adopted wholesale by OfSTED to provide a set of standards by which all schools can be judged, irrespective of character or socio-economic context. Policy makers have often welcomed school effectiveness research because in denying school contexts, such issues as poverty (and the need to do something about social deprivation) are removed from the education debate. Winch argues 'Although some might see school effectiveness research as a rather expensive and highly technical way of stating the obvious, others might see it as the covert imposition of a reactionary alternative common sense about education in the guise of esoteric scientific knowledge.' (1997, p 71)

The School Effectiveness discourse often creates an over-scientific approach - if schools do not meet a rigid set of criteria then they are not considered to be effective, and if improvement is to occur it must be aimed at replicating the prescribed effectiveness factors in the school. This has led to a 'taken for granted set of assumptions about the purpose of schooling and what counts for the benchmarks for determining an effective education' (Slee, Weiner et al. 1998, p 5).

This links with normalisation, a process of ensuring that behaviour judged as normal becomes the only acceptable behaviour. Anything that deviates from the norm can be pathologised, and this can be seen in education, as Hamilton (1997) notes, 
'There is, it appears, a plague on all our schools. Teachers have been infected, school organisation has been contaminated and classroom practices have become degenerative and dysfunctional. In short, schools have become sick institutions. They are a threat to the health of the economic order. Their decline must be countered with potent remedies. Emergency and invasive treatments are called for. Schools need shock therapy administered by outside agencies. Terminal cases merit organ transplants (viz. new heads or governing bodies) ...senior management teams deserve booster steroids to strengthen their macho leadership, while their rank and file colleagues receive regular appraisal administered HRT (human resource technology) to attenuate their classroom excesses' ( $p$ 126).

The inspection system in England and Wales seems to pathologise the 'sick' school, without taking into account the society in which it is positioned. Foucault (1977) writes, 'Like surveillance, and with it, normalisation becomes one of the great instruments of power'. Foucault has identified certain knowledges and practices as central to the 'normalisation' of social principles and institutions of modern society. By 'normalisation' he means the establishment of rules and judgements around the idea of a norm, so that rather than coercing subjects, institutions are judged as successful in so far as they educate people to particular regimes. For schools, this is linked to assessment, appraisal and evaluation, as teachers become agents and subjects of measurements.

There are a number of theoretical perspectives on inspection. Inspections are not straightforward events, but practices which are set within their own tradition and discourse. Wilcox and Gray (1996) see inspection as evaluation, as auditing, as a disciplinary power , and social action and argue that seeing inspection through these theoretical interpretations means that objectivity can not be achieved. They write that 'inspection even in its current OfSTED form does not fit neatly into the usual models of evaluation. It has some of the characteristics of positivist styles of evaluation - use of quantitative methods, the quantification of data, explicit criteria and the like. On the other hand it also draws on some of the practices and assumptions which reflect the interpretive and naturalistic traditions of 
evaluation whilst not necessarily acknowledging that this is the case' (Wilcox and Gray 1996:

115). The positivist nature of some aspects of inspections can be linked to what Power (1994) calls an 'audit explosion' which has been evident in decentralisation of services such as local education authorities and increased control from government. Auditing is often thought of as a neutral collection of facts, but Power notes; 'audits do not passively monitor performance but shape the standards of this performance in crucial ways' (p8).

The discourse of OfSTED involves standards, quality, efficiency, value for money and performance. In order to be successful in a Special Measures Regime, schools need to accept that this discourse is the way forward. If a school is to be removed from Special Measures, it must demonstrate that it has normalised against pre-determined criteria set with which to judge a school, irrespective of the socio-economic environment. Thus all schools have the potential to be 'normalised', and those that are 'abnormal' can be deemed as failing and subject to harsh regimes in the hope that they will 'improve'. Normalisation, therefore, must be grounded in discourse, which sets the boundaries for required reforms. Panoptic performativity is the regime within which teachers and schools can successfully demonstrate their acceptance of the OfSTED and school effectiveness discourse and successfully normalise.

\section{Methodology and research site}

The primary data used in this paper is based on a case study of an inner-city secondary school, 'Northgate' ${ }^{3}$ which was under Special Measures for just under two years ${ }^{4}$. The key research method was analysis of semi structured interviews with teachers which were undertaken in Year A whilst the school was still under Special Measures, then in the following year (B) during a subsequent period of research into life after Special Measures. I interviewed the teachers who had worked at the school when it originally went into Special Measures. There were thirteen teachers in all, out of around forty in the school as a whole. This low number reflects the high turnover in a school under Special Measures. In Year A, two were

\footnotetext{
${ }^{3}$ this is a pseudonym to protect the identity of the school and respondents

${ }^{4}$ Actual dates withheld to protect anonymity of the school
} 
senior management, two were heads of faculty, two were heads of year, four were heads of department, and three were main scale teachers. By Year B, the original group had been reduced to ten, as three had left the school to take up other teaching posts, and the main scale teachers had been promoted to middle management.

Northgate is an 11-16 inner-city comprehensive school, and has a roll of approximately 700 pupils. The school is in an area of significant deprivation. According to the school's OFSTED Report; $^{5}$

The communities served by the school have considerable levels of social and economic disadvantage. Fifty-three per cent of the pupils are entitled to free school meals, a figure which is over double the national average. Forty-four per cent of the pupils speak English as an additional language to their own, representing at least thirty-five different language backgrounds. A significant proportion of these pupils are recent arrivals to the United Kingdom, often as refugees. Thirty-two per cent of the pupils on roll are on the school's register of special educational need, and 21 pupils have a Statement of Special Educational Need, which is above average.

The school went into Special Measures following a visit by HMI. The inspectors identified the key issues for improvement, which can be summarised as curriculum, teaching quality, behaviour, leadership and management, governance, attendance and punctuality. The Inspection report stated, 'Her Majesty's Chief Inspector of Schools is of the opinion that the school requires Special Measures since it is failing to give its pupils an acceptable standard of education'.

The main findings of the report were

- Standards of achievement in lessons were well below average, and the pupils were weak in numeracy and literacy

\footnotetext{
${ }^{5}$ Reference to OfSTED report suppressed to protect anonymity of the school
} 
- Progress in lessons was 'unsatisfactorily slow', with pupils making satisfactory progress in only $25 \%$ of lessons. Pupils were late to lessons, had poor attitudes to learning, and teachers had low expectations

- Pupils exhibited 'distractive or disruptive behaviour' which undermined others' learning. Behaviour in the corridor was also unsatisfactory

- Attendance was poor - a figure of around $80 \%$ was quoted.

- 'Teaching was satisfactory or better in only just over half of the lessons...teachers struggle to implement the plan effectively, manage pupils behaviour sufficiently or match tasks to pupils needs and capabilities' (p4)

- There was a high turnover of staff

- There had been weaknesses in management

- The quality of middle management was unsatisfactory as was the governance of the school

The consequence of being placed into Special Measures was that the school was inspected eight times within eighteen months, an experience I compare to the Panopticon.

\section{Inspection in the Panopticon}

One way to approach the inspection regime under Special Measures is to treat it as a panoptic process. Foucault (1977) suggests that Bentham's Panopticon, a design for a model prison, can be seen as a metaphorical disciplinary mechanism that operates through a variety of institutional apparatuses and discourses. In the Panopticon, individual cells were arranged around a central tower. By the use of backlighting, a supervisor could observe every cell without the 'inmate' knowing if they were being watched or not. Bentham called this 'a new mode of obtaining power of mind over mind in a quantity hitherto without example' (1787, p iii). He wrote that 'the object of the inspection principle is to make them not only suspect, but be assured that whatever they do is known even though that should not be the case' (Bentham in Miller 1988, p 43). Thus institutional authority is invisible, but the objects of 
power, which in a school are the teachers and pupils, are visible and supervised. So used are the prisoners to being constantly watched, that they modify their behaviour and 'even if the inspector no longer keeps a list of future transgressions, even if he never again intervenes, even if he no longer surveys, the prisoners will now begin to do this by themselves: each will watch himself' (Bentham in Miller 1988, p 17). The performative culture in schools lends itself well to the metaphor of the Panopticon and thus, as Harland (1996) notes, 'the exercise of continuing surveillance through the process of monitoring and evaluation means that those concerned also come to anticipate the response...to their actions past, present, and future and therefore come to discipline themselves' ( $p$ 101). Wilcox and Gray (1996) also link inspection with disciplinary mechanisms 'as it requires a school to undergo an exacting discipline which extends over a period considerably longer than that of the inspection week and may also lead to a school being disciplined' (120). They locate the panopticon with the handbook which continues to influence schools in between inspections and is used as a management development tool.

The panoptic metaphor is useful for the experience of being under Special Measures for a number of reasons. First, there is the aspect of continuous observation. When Northgate was under Special Measures, the school was inspected eight times in 18 months, and, in one particular intense phase, five times in nine months. When inspections were occurring at such a rate, there was a sense that they were continuous. Because there was so little 'recovery time' between inspections, the staff learnt to act as if inspection was continuous. The six weeks between inspections was spent gathering evidence for the next time, writing policies, observing and grading lessons and in frantic meetings to ensure the whole school was working together. The experience for teachers was of constant inspections. When interviewed, teachers used metaphors such as 'treadmill', 'jumping over hurdles, 'jumping through hoops' 'a crazy cycle of working like mad followed by a period of near collapse' 'continual grind and grind and grind' and said that 'the frequency of inspections [was] demoralising and exhausting'. Eventually, teachers under Special Measures need to behave as if they are being inspected all the time so it becomes second nature and thus the disciplinary mechanism is internalized. 
Second, there is the experience of inspection as not just constant but all-seeing. To use the panoptic metaphor, even if the school was not being officially inspected, 'the dark central tower' of OfSTED was always invisibly watching. Jeffrey and Wood (1995) write that the major effect of an inspection on primary teachers is not in terms of the result of inspection, but the preparation for it. The urge to present the school in its best light is fuelled by OfSTED's terms of reference: looking for what can be demonstrated by tangible evidence. Thus some teachers see OfSTED as a 'barrack room inspection where they look everywhere, even under your armpits'. (Jeffrey and Woods 1995, p 12)

Third the result was increasing conformity to perceived expectations, the acceptance of the discourse as demonstrated through performativity. Jeffrey and Wood (1995) found that the inspections also had an effect on teaching, with more time going into the plans and less into the lessons themselves, which tended to concentrate on low risk control strategies and not activities designed to enhance pupils' learning. Similarly at Northgate one middle manager, Rob, remarked on 'the idea that nothing is done unless it directly affects the next inspection...we are having to be constantly reactive and unable to be proactive' and Simon, a senior manager, complained,

We don't take risks which is hampering our rate of progress. Also our energies are directed towards completing tasks on the 'must have' tick list rather than focusing on specific examples which we feel are important. Second-guessing will not always hit the mark so we have to cover every eventuality.

This again illustrates the experience of constant inspection and the way teachers felt they needed to modify their behaviour in a permanent way 'because the constant pressure acts even before the offences, mistakes or crimes have been committed' (Foucault 1977 p 206). At Northgate teachers believed they must act as if they were being inspected all the time, in order to 'train' themselves and pupils into expected modes of behaviour, and so that the arrival of an inspector would be seen as normal. During OfSTED inspections 'the nature of the 
audit influences performance, and schools change their practices to conform to what they think the inspectors inspect' (Earley 1998, p 172). Thus a school becomes 'an organisation for 'the gaze' and for the avoidance of 'the gaze" (Ball 1997, p 332). This was certainly the case at Northgate which increasingly seemed like an organisation existing purely for the purposes of 'passing' an inspection. Indeed 'the school became a sort of apparatus of uninterrupted examination' (Foucault 1977, p 186), although in this case the examination was of teachers and not of pupils.

\section{Panoptic Performativity}

Panoptic performativity can describe the experience of an inspection regime in that teachers and pupils feel as if they are constantly being observed, and perform accordingly in order to escape the regime. The discourse of OfSTED and School Effectiveness must be accepted in order for normalisation to be accomplished, and only when normalisation is achieved can the escape from the Panopticon be accomplished. As prisoners in Bentham's prison knew that they must exhibit 'good' behaviour at all times, teachers at Northgate knew how and what they had to perform. It is important to point out here that I am not arguing that improvement at Northgate was not necessary. Clearly there were good reasons why the school was put into Special Measures. However, the intensity of the process, and the pressure to perform 'improvement' in a predefined way is not necessarily the best way to encourage lasting change. 
The effects of panoptic performativity were particularly clear in the period in which Northgate was under Special Measures. Changes in discourse and performance were increasingly obvious as the inspection period continued. For a school like Northgate, adopting the discourse of OfSTED was a key strategy in terms of getting out of Special Measures. Under an inspection regime, a school's documentation becomes part of the surveillance. 'Particular features of the observed individual are differentially encoded in written reports and files and organised into general registers and the cumulative systems. These techniques and methods of documentation facilitate the description and analysis of individuals and groups' (Smart 2002, p 87). In schools this can be seen in constant clarifications of policies and procedures, in departmental handbooks, school and departmental action plans. Ball (1997) notes, 'documents produced in these technologies become increasingly reified, self referential and dislocated from the practices they are 'meant' to stand for or account for' ( $p$ 319). Under the OfSTED regime, and particularly under Special Measures there is no freedom of expression- unless a school 'behaves' and 'jumps through the hoops', it will not be released from the regime.

For example, the self-evaluation documentation produced by Northgate over the inspection period increasingly mirrored the language of OfSTED. Even the appearance of the documentation differed. The first Head teacher's Report, produced for the first inspection is five sides of closely typed paper, stapled together. The ninth report, by now grandly entitled 'Head teacher's Self Evaluation of Progress Under Special Measures' was spiral bound with laminated covers, had a three-colour title page, and was 47 pages long.

Similarly, the content of the documentation changed to fit the OfSTED model in a process of continuous and pervasive normalisation. The short comment on key issue 2 (Raise Standards across the Curriculum) in the first report was a practical guide to developments such as the introduction of lesson observations and the standardisation of schemes of work. The ten pages allocated to this issue in the ninth report detailed self-review, performance review, teaching and learning policy, monitoring of teaching, training and improved planning and was clearly a direct response to the OfSTED report following the previous inspection. Successive 
Head teacher's Reports demonstrated the increased adoption of the discourses of the inspection, in part through a direct emulation of the language of the OfSTED reports. For example, the first Head teacher's report commented briefly on 'the introduction of a school based schedule of lesson observations'. In the following March, OfSTED remarked that 'there is no clear consensus as to the aims of teaching and learning - there is a need for a teaching and learning policy which should guide each department's teaching'. The subsequent June Head teacher's Self Evaluation discussed at length the newly established Teaching and Learning Policy, and the following inspection report noted 'an interim teaching and learning policy provides an extensive range of helpful advice about, for example, teaching and learning strategies, marking and how to edit the pupils' work.' Similarly in one inspection HMI noted that 'a system is needed which can judge conclusively the proportion of good and satisfactory teaching'. The Headteachers' Evaluation then noted that 'the quality of teaching will be monitored by a structured programme of lesson observations', and the following inspection responded 'the school has responded positively to criticism in the previous monitoring visit report by implementing an appropriate system for monitoring the quality of teaching'.

As well as adopting the correct discourse in documentation, teachers at Northgate quickly leant the way to perform. They saw it as a pragmatic and temporary way of 'getting off Special Measures', not as a permanent change.

We basically have always had the impression that we'll jump through hoops, we'll get off Special Measures and then we'll take our school back. We'll do what we have to do to get off Special Measures, we don't like doing it and we'll play the game. Simon, senior manager

Between and during inspections, lessons at Northgate were run to a strict formula and the Headteacher and senior management team monitored this rigorously. When being inspected, teaching a 'good' lesson increasingly resembled a driving test, in which failure could result from one incorrect three-point turn despite the success of all the other manoeuvres. lan, a senior manager noted the need to follow the school improvement recipe exactly 
They told us what to do, they said 'this is what you need to do, you need to set up an assessment procedure to prove that everybody's improving' and that's what we did and we managed to prove it surprise, surprise and so we came off Special Measures, we only did what we were told to do. lan

At Northgate the teachers followed a closely prescribed recipe of what was considered a good lesson. None of these were particularly contentious within the school, but awareness of the need to follow a recipe was disempowering, as lan describes:

We got very, very good at applying the very bland OfSTED model to our teaching. Why don't you get OfSTED to come and analyse theatre plays and concerts because they know the exact formula that makes them successful and satisfactory? We got very good at producing OfSTED satisfactory type lessons and I'm sure we did and I'm sure everybody in the school knows exactly what to do and if I had a clean slate and I wanted to really make a class fly I certainly wouldn't write bloody lesson objectives on the board at the start, because the whole point is to keep them guessing what the lesson is 'what is this about, where's it leading to, what is he going to do' and at the end it should all fall into place. This three-part lesson is all very well but teaching is an art as well as a science, and if you take all the artistry out of it where is it going to go? I think we got very, very good at doing it according to the OfSTED model and we had to do that and we did do that. Ian, senior manager

Similarly, Ball $(2001, \mathrm{p} 8)$ remarks that under inspection 'what is produced is a spectacle or what we might see as an 'enacted fantasy' which is there to be seen and judged'. He goes on to say that 'the heart of the educational project is gouged out and left empty. Authenticity is replaced by plasticity' ( $\mathrm{p} 12$ ). Alistair, a middle manager agreed saying that 'I had a guide book once, and it was describing a town in France as being 'much got up for the tourists', and I think that schools being OfSTEDed are 'much got up for the inspectors'.' 
At Northgate, students remarked on the 'unnatural' lessons 'performed' in front of inspectors: 'when the inspectors are in our lessons the students stop talking and when the inspectors go the students start taking again and that is so stupid. You don't have to pretend, just be yourself', 'people would start behaving, teachers would teach', 'the teachers start to patronise and pretend that they are nice and teach us properly for once'.

Mark, a middle manager, likened the whole experience to a game played according to a closely prescribed set of rules

You play the game, because they tell you what they want, then you do it and they come and say 'wow, you've done that'. It's a bizarre game. When HMI were here you had to go through the exact system the school had in place, just to show them that the school did have the system.

Such performativity in education can lead to a sense of deprofessionalisation as teachers can feel that they are performing in order to demonstrate their competence. According to Jeffrey and Woods (1996,p 326) 'OfSTED inspections...penetrate to the heart of teachers' operations and mount a continual surveillance. The teacher's self is brought under intensive and critical gaze'. At Northgate there was clear resentment at the externally dictated agenda:

Things arise that are imposed on me and I find that a lot more tiring when I've got to do something for somebody else, it's a different sort of work. Simon, senior manager

Whereas when you're under Special Measures you are very much tied to a formula and you can't change that, you can't vary it, you can't experiment, you're just tied, because that's what they want to see. Alistair, middle manager

When you're in Special Measures because you have to teach to the equation dictated by the HMI inspectors which isn't necessarily real learning and teaching, Janice, middle manager 
You can't really experiment with anything very much while you're in Special Measures you can't try new things out, you can't say 'we won't do that project lets do this because something's come up Rob, middle manager

This sense of disempowerment, of a school where the entire effort is directed towards meeting the demands of an externally imposed agenda, perhaps indicates why schools can sometimes suffer a period of decline once released from the regime.

\section{Conclusion}

Panoptic performativity worked at Northgate, Teachers learned to perform according to the norms dictated by the inspection regime. Because of the intensity of the inspections there was a real sense of constant surveillance, and as teachers learned to behave as if they were being inspected all the time, they learned to perform 'the game' with efficiency and after twenty two intensive months, Northgate's final inspection report noted 'in accordance with Section 14 of the Schools Act 1996, I am of the opinion that the school no longer requires Special Measures, since it is now providing an acceptable standard of education for its pupils'. The report noted that good progress had been made on all key issues, praising the leadership of the Headteacher, a rise in standards of attainment and pupil progress, the behaviour and positive attitudes of the pupils and the quality of teaching and learning. The report concluded, 'the school is successful in providing for its pupils in very challenging circumstances. It is now popular with parents and places for next September's Year 7 are oversubscribed'. Clearly the school had needed intervention in order to improve standards of education, and the regime of panoptic performativity had enabled the school to come out of Special Measures.

However, teachers and school governors in England live in fear of 'going into Special Measures' and the panoptic regime is seen as something that that needs to be survived. 
This has the consequence of schools struggling to come out of Special Measures and making changes that can often be short-term and cosmetic. Life under Special Measures can hardly be described as 'just a gaze, an inspecting gaze' (Foucault 1977, p 155). Rather, for the recipient, OfSTED seems to have

so many powers, from the slow illumination of obscurities, the ever prudent reading of the essential ... and the majestic confiscation of paternal authority are just so many forms in which the sovereignty of the gaze gradually establishes itself - the eye that knows and decides, the eye that governs (Foucault 1963, p 89).

Clearly in coming out of Special Measures, Northgate had been successful, and perhaps the punitive nature of the Special Measures regime should be seen in the this context. However, a regime which dictates that the normal is defined externally, where teachers earn to perform the normal under an intense and seemingly omniscient gaze seems too artificial a scenario to engender permanent change. When the 'gaze' leaves, what then for the school? Is the Panoptic prisoner truly reformed, or do schools released from the regime suffer an inevitable decline? Is the normalisation truly internalised? 